\title{
Unusual switchable peroxidase-mimicking nanozyme for the deter- mination of proteolytic biomarker
}

\author{
Claire McVey ${ }^{1}$, Natasha Logan ${ }^{1}$, Nguyen T. K. Thanh ${ }^{2,3}$, Christopher Elliott ${ }^{1}$, and Cuong Cao ${ }^{1,4}$ \\ ${ }^{1}$ Institute for Global Food Security, School of Biological Sciences, Queen's University Belfast, 18-30 Malone Road, Belfast, BT9 5BN, UK \\ ${ }^{2}$ Biophysics Group, Department of Physics and Astronomy, University College London, London, WC1E 6BT, UK \\ ${ }^{3}$ UCL Healthcare Biomagnetic and Nanomaterials Laboratories, 21 Albemarle Street, London W1S 4BS, UK \\ ${ }^{4}$ Material and Advanced Technologies for Healthcare, Queen's University Belfast, 18-30 Malone Road, Belfast, BT9 5BN, UK
}

(C) The authors 2018. This article is published with open access at link.springer.com

Received: 16 August 2018 / Revised: 22 October 2018 / Accepted: 6 November 2018

\begin{abstract}
Detection of enzyme biomarkers originating from either bio-fluids or contaminating microorganisms is of utmost importance in clinical diagnostics and food safety. Herein, we present a simple, low-cost and easy-to-use sensing approach based on the switchable peroxidase-mimicking activity of plasmonic gold nanoparticles (AuNPs) that can catalyse for the oxidation of 3,3',5'5-tetramethylbenzidine (TMB) for the determination of protease enzyme. The AuNP surface is modified with casein, showing dual functionalities. The first function of the coating molecule is to suppress the intrinsic peroxidase-mimicking activity of AuNPs by up to $77.1 \%$, due to surface shielding effects. Secondly, casein also functions as recognition sites for the enzyme biomarker. In the presence of protease, the enzyme binds to and catalyses the degradation of the coating layer on the AuNP surface, resulting in the recovery of peroxidase-mimicking activity. This is shown visually in the development of a blue colored product (oxidised TMB) or spectroscopically as an increase in absorbance at 370 and $650 \mathrm{~nm}$. This mechanism allows for the detection of protease at $44 \mathrm{ng} \cdot \mathrm{mL}^{-1}$ in $90 \mathrm{~min}$. The nanosensor circumvents issues associated with current methods of detection in terms of ease of use, compatibility with point-of-care testing, low-cost production and short analysis time. The sensing approach has also been applied for the detection of protease spiked in ultra-heat treated (UHT) milk and synthetic human urine samples at a limit of detection of 490 and $176 \mathrm{ng} \cdot \mathrm{mL}^{-1}$, respectively, showing great potential in clinical diagnostics, food safety and quality control.
\end{abstract}

\section{KEYWORDS}

gold nanoparticles, peroxidase-mimicking, nanozyme, enzyme detection, biomarkers

\section{Introduction}

The sensitive and rapid detection of enzymes can reveal the early onset of infection [1], inflammation [2], or contamination [3] and thus is of critical importance in clinical diagnostics and food safety. For example, proteolytic enzymes, which form one of the largest and most diverse enzyme family, have attracted significant attention due to their physiological involvement in all life functions [4]. Proteases are tightly regulated by complex endogenous pathways under physiological conditions [5], however their dysregulation can result in the progression of diseases such as Alzheimer's [6], Parkinson's [7], pulmonary emphysema [8], cardiac disease [9], fibrinolysis [10], thrombosis [11], and impaired mitochondrial function [12]. Myeloblastin (proteinase 3), a serine protease, is also elevated in the urine of patients with diabetic kidney disease, caused by endothelial dysfunction and glomerular inflammation [13]. There is also growing evidence that suggests a link between protease activity and infections of the gastrointestinal tract [14] and infected wounds [15]. Similarly, an elevation of proteases can reveal diseases in animals, i.e. increased protease activity in cow milk can be an indication of bovine mastitis caused by microorganisms such as Staphylococcus aureus and Streptococcus uberis [16]. Proteases produced by foodborne bacteria via contaminated meat and dairy products can lead to rancidity, and decreased shelf life and quality of food products [17]. Therefore, proteolytic enzymes can be considered as an important biomarker of disease, bacterial infection and contamination. Early detection of the proteolytic biomarker can ultimately allow clinical diagnosis and intervention, resulting in an improved prognosis, treatment and monitoring of human and animal health. In the food production industry, identification of proteases can also provide an early indication of bacterial contamination in food, thus eliminating non-compliance at the early stage of the food chain, ensuring food safety, quality and protection of consumer health.

Widely exploited methods for the detection of enzyme biomarkers (e.g. protease) in clinical and veterinary samples include twodimensional (2D) gel electrophoresis [18], biochemical and immunological assays [19, 20], and mass spectrometry [21]. Recently, research has focused on the use of nanotechnology to provide rapid sensing of enzymes as biomarkers of infectious diseases, i.e. using nanocantilever [22], quantum-dots [23], plasmonics-based [24], and other surface enhanced-based approaches $[25,26]$, to overcome limitations in terms of labour intensiveness, long analysis time and non-conduciveness to point-of-need testing. In particular, enzyme mimics or nanozymes, derived from nanomaterials have initiated significant curiosity in the fields of biological sensing and bio-medicine. These artificial enzymes are designed to imitate the properties of natural enzymes by increasing the catalytic rate of reaction. Importantly, nanozymes have the potential to overcome the inherent problems of natural enzymes, such as poor stability (denature) and high 
preparation and purification costs. Furthermore, the superiority exhibited by nanozymes, including tunability and even switching of enzyme-mimicking activity has led to the development of functional nanomaterials for bio-sensing applications [27].

Peroxidases are defined as a group of enzymes that catalyse the oxidation of substrates in the presence of hydrogen peroxide $\left(\mathrm{H}_{2} \mathrm{O}_{2}\right)$. For instance, horseradish peroxidase enzyme (HRP) is the predominant peroxidase enzyme used in enzyme-linked immunosorbent assays (ELISAs) for the detection of a multitude of targets including bacterial pathogens [28]. Gold nanoparticles (AuNPs) possess weakly bound reactive species such as oxygen atoms on their surface, which leads to improved peroxidase-mimicking activity over other noble metals such as silver, copper, platinum and palladium [29]. This intrinsic peroxidase-mimicking activity of AuNPs, when merged with their ease of synthesis, biocompatibility and tunability, makes them excellent candidates for nanosensor design. Thus, studies have focused on the suppression and enhancement of peroxidase-mimicking activity of AuNPs for the detection of $\mathrm{H}_{2} \mathrm{O}_{2}$, glucose, DNA and heavy metals. Functional molecules such as aptamers, DNA, antibodies, as well as cystamine and heavy metals have been utilised to tune the enzyme-mimicking activity of AuNPs in the design of biological sensors [30-33].

In this work, we present an unusual switchable peroxidasemimicking activity of AuNPs for the detection of protease, which plays a significant role in clinical manifestations and food safety. Compared to similar methods for the detection of protease enzyme utilising AuNPs, the current approach has improved ease-of-use, can be carried out in $90 \mathrm{~min}$ in a label-free manner, and does not require complicated and expensive equipment. For an overview of AuNP based platforms for the detection of proteases, see Table S1 in the Electronic Supplementary Material (ESM). Finally, we have also demonstrated the potential applicability of the nanosensor in bovine ultra-heat treated (UHT) milk and synthetic human urine for the detection of protease, a biomarker indicative of human or animal diseases or food spoilage.

\section{Experimental section}

\subsection{Reagents and chemicals}

Sodium citrate tribasic dehydrate $\left(\mathrm{HOC}(\mathrm{COONa})\left(\mathrm{CH}_{2} \mathrm{COONa}\right)_{2} \cdot 2 \mathrm{H}_{2} \mathrm{O}\right)$, hydrogen tetrachloroaurate(III) $\left(\mathrm{HAuCl}_{4} \cdot 3 \mathrm{H}_{2} \mathrm{O}\right)$, phosphate buffer saline (PBS), acetic acid $\left(\mathrm{CH}_{3} \mathrm{COOH}\right)$, sodium acetate $\left(\mathrm{CH}_{3} \mathrm{COONa}\right)$, casein (technical grade), sodium chloride $(\mathrm{NaCl})$, hydrogen peroxide $\left(\mathrm{H}_{2} \mathrm{O}_{2}\right)$, protease from bovine pancreas (type $\mathrm{I}, \geq 5$ units/mg solid, EC Number 232-642-4), catalase (bovine liver), lipase (Candida rugosa), amylase (porcine pancreas), horseradish peroxidase enzyme (HRP), hydrochloric acid $(\mathrm{HCl})$ and Surine ${ }^{\mathrm{Tx}}$ negative urine control (certified reference material, used directly with no further preparation steps) were purchased from Sigma Aldrich (UK). 3,3,5,5'-Tetramethylbenzidine (TMB) was purchased from Thermo Fisher Scientific (UK). $0.45 \mu \mathrm{m}$ filters were purchased from MerckMillipore (Germany). UHT skimmed milk ( $0.3 \%$ fat) was purchased from a local supermarket (Tesco).

\subsection{Gold nanoparticle synthesis}

AuNPs (with an average diameter of $13 \mathrm{~nm}$ ) were synthesised by the Turkevich method [34] with minor alterations. In a typical experiment, $2.0 \mathrm{mM} \mathrm{HAuCl}_{4} \cdot 3 \mathrm{H}_{2} \mathrm{O}$ was dissolved in $50 \mathrm{~mL}$ de-ionised $\mathrm{H}_{2} \mathrm{O}$ and heated to reflux under constant stirring $(t \sim 10 \mathrm{~min})$. Sodium citrate $(3.5 \mathrm{mM})$ was quickly injected and the solution was removed from the heat upon the color change from translucent yellow to wine red.

\subsection{Modification of gold nanoparticle surface with casein}

To $1.0 \mathrm{~mL}$ of freshly prepared AuNPs (optical density measured at $\left.520 \mathrm{~nm}, \mathrm{OD}_{520 \mathrm{~nm}}=3.0\right), 100 \mu \mathrm{L}$ of $0.1 \mathrm{mg} \cdot \mathrm{mL}^{-1}$ casein prepared in $0.1 \mathrm{M}$ PBS ( $\mathrm{pH} 7$ ) was added. The solution was incubated overnight at room temperature, however it was noted that 60 min incubation was sufficient to ensure AuNP stability. The particles were subsequently centrifuged at $15,682 \mathrm{~g}$ for $60 \mathrm{~min}$ to remove residual casein and re-suspended in $0.1 \mathrm{M}$ PBS buffer ( $\mathrm{pH} 7$ ). The coated particles were stored at $4{ }^{\circ} \mathrm{C}$ prior to analysis.

\subsection{Determination of Michaelis-Menten parameters}

Bare and casein-AuNPs were incubated with TMB (0-1.0 mM) and varying $\mathrm{H}_{2} \mathrm{O}_{2}$ concentrations $(0.0075 \%-6.0 \%)$ at room temperature for $10 \mathrm{~min}$. Absorption values at $370 \mathrm{~nm}$ were measured. For further information on the calculation of parameters see the ESM.

\subsection{Detection of enzyme using coated AuNP}

In a typical experiment, 0.1 M PBS buffer ( $\mathrm{pH} 7$ ) was used to prepare casein-coated AuNPs and protease to assure the enzymatic cleavage activity. $100 \mu \mathrm{L}$ of $44.43 \mathrm{pM}$ coated-AuNP were incubated with $50 \mu \mathrm{L}$ of protease at $37{ }^{\circ} \mathrm{C}$ for $60 \mathrm{~min}$. Subsequently, $150 \mu \mathrm{L}$ solution of $1.0 \mathrm{mM} \mathrm{TMB} / 6.0 \% \mathrm{H}_{2} \mathrm{O}_{2}$ was added and incubated at room temperature for $30 \mathrm{~min}$.

\subsection{Detection of protease enzyme using casein modified AuNP in UHT milk and urine samples}

Milk was centrifuged at $15,682 g$ for $60 \mathrm{~min}$ and filtered using a 0.45 $\mu \mathrm{m}$ Millipore filter. It was then diluted 1:50 in PBS buffer $(0.1 \mathrm{M}$, $\mathrm{pH}$ 7.0). Various protease concentrations $\left(0-5 \mathrm{mg} \cdot \mathrm{mL}^{-1}\right)$ were spiked into the prepared milk and analysis carried out as above. Protease was spiked into urine (used directly with no further preparation) at various concentrations $\left(0-5 \mathrm{mg} \cdot \mathrm{mL}^{-1}\right)$ and the assay was carried out as above.

\subsection{Instrumentation for characterization}

Optical absorbance spectrophotometry measurements were carried out using a Cary 60 spectrophotometer (Agilent Technologies, USA) and a Tecan Safire plate reader (Tecan, Switzerland). Particle size and zeta potential measurements were carried out using a Zetasizer NanoZS (Malvern, UK). An Eppendorf centrifuge model 5415R (Germany) was used throughout the experimental development. Transmission electron microscopy (TEM) characterization was acquired using a FEI Tecnai F20 operated at $200 \mathrm{kV}$.

\section{Results and discussion}

The working principle of the developed method for the detection of enzyme biomarkers is demonstrated in Fig. 1. The method utilises AuNPs which exhibit strong peroxidase-mimicking activity, i.e. catalysing for the oxidation of 3,3'5,5'-tetramethylbenzidine (TMB) in the presence of $\mathrm{H}_{2} \mathrm{O}_{2}$ to generate a blue colored product $\left(3,3,5,5^{\prime}\right.$ tetramethylbenzidine diimine, oxTMB). Casein is a typical substrate for protease digestion [35]. Our study revealed for the first time that when AuNPs are coated with casein, the strong peroxidasemimicking activity of AuNPs is suppressed. In the presence of a protease from bovine pancreas (an endoproteinase, EC Number 232-642-4), the enzyme catalyses for the degradation of the casein layer on the AuNP surface, thereby recovering the strong peroxidase-mimicking activity of the AuNPs. The oxidative product derived from TMB provides a color indicator, therefore there is no requirement for expensive read-out equipment. Because casein can be degraded by almost all serine, cysteine, metallo, and aspartic proteases [36], the approach developed in this work is therefore suitable for the identification of broad, total protease activity. The concept also suggests that sequence-specific proteases could also be detected if an appropriate protein or peptide substrate is used for the coating. 
(a) Peroxidasemimicking activity of AuNPs

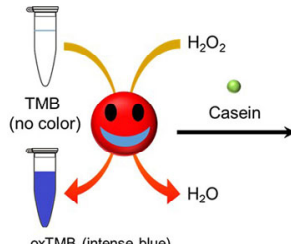

OxTMB (intense blue)
Strong peaks @ $@ 370$ and $650 \mathrm{~nm}$

Strong nanozyme activity

Suppressed nanozyme activity (by $77.1 \%$ ) (b) Coating with casein

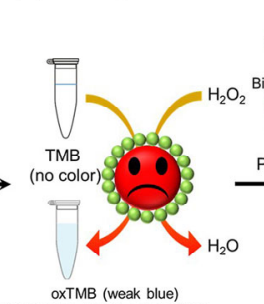

(c) In the presence of
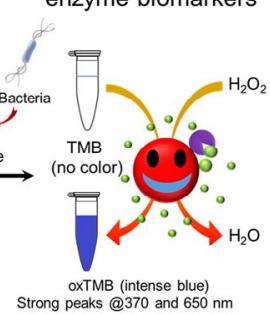

oxTMB (intense blue)
Strong peaks @ 370 and 650 nm

Recovered nanozyme activity enzyme biomarkers o Casein Enzyme biomarker (e.g. protease)

Figure 1 Overall scheme demonstrating the switching of peroxidase-mimicking activity of casein coated AuNPs for the detection of enzyme biomarkers. (a) AuNPs possess the peroxidase-mimicking ability to catalyse the oxidation of TMB in the presence of $\mathrm{H}_{2} \mathrm{O}_{2}$, resulting in oxTMB which exhibits a blue color and strongly absorbs light at 370 and $650 \mathrm{~nm}$. (b) When casein is coated onto the AuNP surface, this peroxidase-mimicking activity is suppressed, resulting in a weakened absorbance at 370 and $650 \mathrm{~nm}$. (c) In the presence of protease derived from bio-fluids or microorganisms, hydrolytic cleavage of the surface shielding layer (casein) results in the recovery of the peroxidase-mimicking activity of AuNP.

The optimal concentration of casein coated onto the AuNP surface (average diameter of $13 \mathrm{~nm}$ ) was determined and particles were subsequently incubated with $0.1 \mathrm{mg} \cdot \mathrm{mL}^{-1}$ casein. This concentration was sufficient to suppress the peroxidase-mimicking activity of AuNPs, as shown by the diminishment of absorption peak at $370 \mathrm{~nm}$ in the presence of $1.0 \mathrm{mM} \mathrm{TMB}$ and $6.0 \% \mathrm{H}_{2} \mathrm{O}_{2}$ (Fig. $\mathrm{S} 2$ in the ESM). Coated particles were then centrifuged to remove any unbound residues and suspended in phosphate buffer saline (PBS, $0.1 \mathrm{M}, \mathrm{pH}$ 7). In Fig. 2(a), the casein-AuNP conjugates demonstrate a peak absorbance at $525 \mathrm{~nm}$. A shift in wavelength was noted in comparison to the bare-AuNP $(519 \mathrm{~nm})$ which is indicative of increased refractive index around the particle surface, caused by adsorbed layers of casein [37]. The absorbance ratio at 650 and $520 \mathrm{~nm}$ was calculated to ensure the coated-AuNPs had not aggregated as a result of the coating procedure. Calculating this ratio provides detail about the level of aggregation as the absorbance values at $650 \mathrm{~nm}$, which is the typical wavelength shift generated by AuNP aggregation, and $520 \mathrm{~nm}$ which is the typical wavelength of the dispersed, citrate-stabilised AuNPs subsequent to synthesis. A higher ratio would indicate AuNP aggregation. It was determined that there was no significant difference in the absorbance ratio at 650 and $520 \mathrm{~nm}$ between the uncoated-AuNPs and casein coated-AuNPs $(p=0.42)$ (Fig. 2(a)). The $p$-value is the calculated probability, e.g. a $p$-value $>0.05$ indicates that the results are not statistically significant. To determine the stability of the casein coated-AuNPs, they were exposed to a high electrolyte medium (Fig. 2(a)). The results demonstrate no statistical difference between casein-coated particles in the absence and presence of $2.0 \mathrm{M} \mathrm{NaCl}$ ( $p=0.37$ ). In addition, full width half maximum (FWHM) calculations also demonstrated no peak broadening of spectra for casein-coated AuNPs in the presence of $2.0 \mathrm{M} \mathrm{NaCl}$ (FWHM $=70.60 \mathrm{~nm}$ ) compared to uncoated-AuNPs (FWHM $=70.02 \mathrm{~nm}$ ). Peak position for FWHM measurement was 519 and $525 \mathrm{~nm}$ for the uncoatedAuNPs and casein-AuNPs, respectively. Thus, this demonstrates that the AuNPs were successfully coated with and strongly stabilized by casein. Casein contains carboxyl, hydroxyl, and amine functional groups which can self-assemble onto the AuNP surface. The casein molecule also consists of both polar and non-polar parts which renders the molecule both hydrophobic and hydrophilic. The hydrophobic polymer blocks tend to adsorb onto the AuNP surface (contributing to the stabilisation of the particle), whilst the hydrophilic parts of the casein molecule render them dispersible in an aqueous solution [38]. This would explain the high stability of casein-coated AuNPs observed in the presence of a high electrolyte medium. The casein-coated AuNPs can be rapidly produced and have good stability and function when stored for at least 4 weeks at $4{ }^{\circ} \mathrm{C}$ in PBS buffer (0.1 M, pH 7).

Zeta-potential measurements were conducted with the bare- and casein-coated AuNPs to determine surface charge (Fig. 2(b)). The citrate reduced bare-AuNPs have a zeta-potential of $-46.6 \pm 2.58 \mathrm{mV}$. In contrast, the casein-AuNPs exhibit a zeta-potential of $-19.1 \pm$ $2.73 \mathrm{mV}$. Casein micelles are positively charged, containing mixed charged regions at $\mathrm{pH} 7$ [39]. This would suggest that casein can effectively shield and partially compensate the negative-citrate charges on the nanoparticle surface (do not displace), thus effectively suppressing the peroxidase-mimicking activity of the AuNPs in the presence of $\mathrm{TMB} / \mathrm{H}_{2} \mathrm{O}_{2}$. Hydrodynamic size of bare AuNPs (13.9 \pm $2.9 \mathrm{~nm})$ and casein-AuNPs $(14.4 \pm 1.8 \mathrm{~nm})$ was determined using dynamic light scattering (DLS) technique. TEM analysis was also carried out (Fig. S3 in the ESM). The as-prepared casein-AuNPs demonstrate a size diameter of $14.36 \pm 3.0 \mathrm{~nm}$, in comparison to the bare-AuNP $(13.0 \pm 2.2 \mathrm{~nm})$.

AuNPs acting as an artificial nanozyme for the oxidization of TMB are evidenced in Fig. 3. Figure 3(a) demonstrates a vivid blue color formation due to the peroxidase-mimicking activities of AuNPs in the presence of $1.0 \mathrm{mM}$ TMB and $6.0 \% \mathrm{H}_{2} \mathrm{O}_{2}$. The images also provide evidence that AuNPs are required to oxidise TMB, because $\mathrm{TMB}$ or $\mathrm{TMB} / 6.0 \% \mathrm{H}_{2} \mathrm{O}_{2}$ solution on its own cannot be converted into the oxidized form under the set conditions (thus not exhibiting the blue color). Figure 3(b) demonstrates the development of the charge-transfer complex absorption peaks at 370 and $650 \mathrm{~nm}$ for AuNPs in the presence of $\mathrm{TMB} / \mathrm{H}_{2} \mathrm{O}_{2}$ (purple line), which are indicative of TMB oxidisation reaction [40]. AuNPs display a plasmonic peak around $520 \mathrm{~nm}$ (Fig. 3(b), black line). To the best of our knowledge, the peak absorbance at $650 \mathrm{~nm}$ has been frequently used as a diagnostic peak in previous studies which exploited the peroxidase-mimicking property of AuNPs [30-33]. However, chemical and physical interferences may have the potential to induce AuNP aggregation, particularly in a medium with high electrolyte content, resulting in a red-shift of the plasmon peak around $650-700 \mathrm{~nm}$. Therefore, the absorption peak at $650 \mathrm{~nm}$, indicative of the oxTMB product, is less useful in this approach due to the potential overlap of the nanoparticle aggregation peak.

Furthermore, it is well known that AuNP size and catalytic activity is inversely proportional, i.e. increasing AuNP size results in decreasing catalytic activity [29].
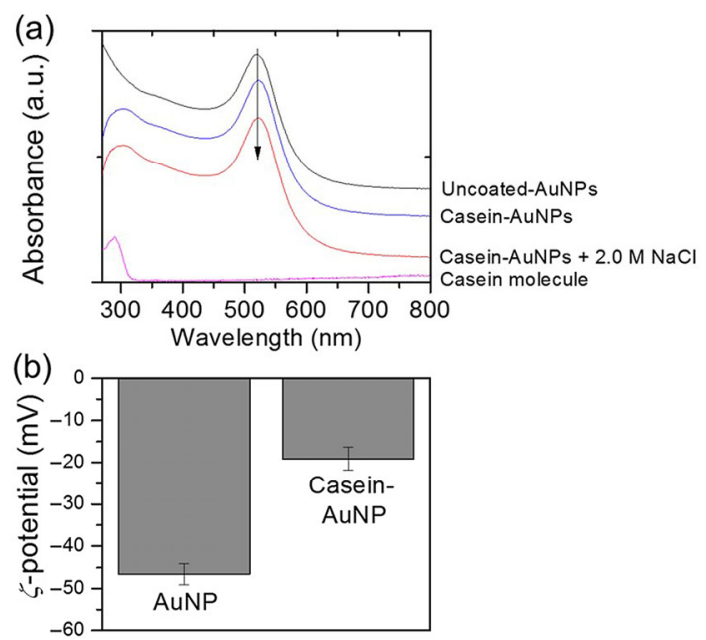

Figure 2 (a) UV-Vis analysis (offset for clarity) of uncoated-AuNPs (black) and casein-AuNP (blue). Stability analysis was carried out in the presence of $2.0 \mathrm{M}$ $\mathrm{NaCl}$, demonstrating no wavelength shift for the coated-AuNPs, indicating successful functionalisation. The pink line indicates the full spectrum analysis of casein. (b) Zeta-potential of uncoated AuNPs and casein-coated AuNPs. 

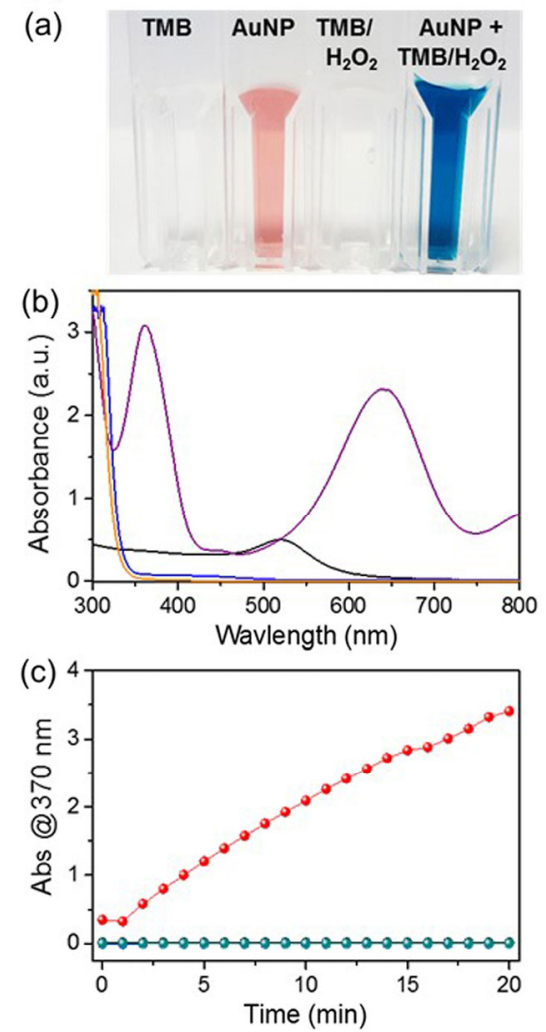

Figure 3 Peroxidase-mimicking activity of AuNPs (concentration of AuNPs = $44.43 \mathrm{pM}$ ). (a) Representative color images demonstrating the catalysed reaction of $1.0 \mathrm{mM} \mathrm{TMB} / 6.0 \% \mathrm{H}_{2} \mathrm{O}_{2}$ solution in the presence and absence of AuNPs. (b) UV-Vis spectroscopic analysis of catalysed reaction of $\mathrm{TMB} / \mathrm{H}_{2} \mathrm{O}_{2}$ in the absence (blue curve) and presence of AuNPs (purple curve). The black and orange line demonstrates the spectra for bare AuNPs on their own and $1.0 \mathrm{mM}$ TMB, respectively. (c) Kinetic analysis of the catalysed reaction for $1.0 \mathrm{mM}$ $\mathrm{TMB} / 6.0 \% \mathrm{H}_{2} \mathrm{O}_{2}$ in the presence of AuNPs (red line) measured at $370 \mathrm{~nm}$. The cyan and black line (overlapped) demonstrates the kinetic analysis for TMB and $\mathrm{TMB} / \mathrm{H}_{2} \mathrm{O}_{2}$, respectively, in the absence of AuNPs. All reactions carried out for $20 \mathrm{~min}$ at room temperature.

In terms of the casein-AuNP nanosensor for protease detection, monitoring the absorbance at $650 \mathrm{~nm}$ could give rise to falsenegative or false-positive results. Based on this, we proposed to use the peak at $370 \mathrm{~nm}$ to quantify the peroxidase-mimicking activity of AuNPs which has not been exploited heretofore. The results also demonstrate a time-dependent increase in absorbance at $370 \mathrm{~nm}$ for AuNPs in the presence of $\mathrm{TMB} / \mathrm{H}_{2} \mathrm{O}_{2}$ (Fig. 3(c), red). This data provides important insight into the peroxidase-mimicking activity of AuNPs.

Kinetic analysis was performed by mixing a fixed concentration of AuNPs with various concentrations of $\mathrm{TMB} / \mathrm{H}_{2} \mathrm{O}_{2}$ and monitoring TMB oxidation by absorption analysis at $370 \mathrm{~nm}$. As shown in Fig. 4(a), the peroxidase-mimicking activity of AuNPs strongly depends on $\mathrm{H}_{2} \mathrm{O}_{2}$ concentration. The maximal velocity $\left(V_{\max }\right)$ is a useful parameter in determining the maximum conversion of substrate to product via natural enzyme (i.e. HRP) or nanozyme (i.e. AuNP) at the point where the active sites are fully saturated. When the $\mathrm{H}_{2} \mathrm{O}_{2}$ increases from $0.0075 \%$ (which has been already included in the commercial TMB solution) to $6.0 \%$, the maximum rate of reaction $\left(V_{\max }\right)$ increases accordingly from $4.9 \times 10^{-7}$ to $4.4 \times$ $10^{-6} \mathrm{M} \cdot \mathrm{min}^{-1}$, respectively. More details about the kinetic parameters are summarized in Fig. S4 and Table S5 in the ESM. From a practical point of view, clinical and veterinary samples may contain a certain level of peroxidase enzymes which in turn could potentially interfere with the gold nanozyme activity. To understand the potential interferences, kinetic analysis was also carried out for HRP enzyme as shown in Fig. 4(b). Indeed, HRP can catalyse for the oxidation of
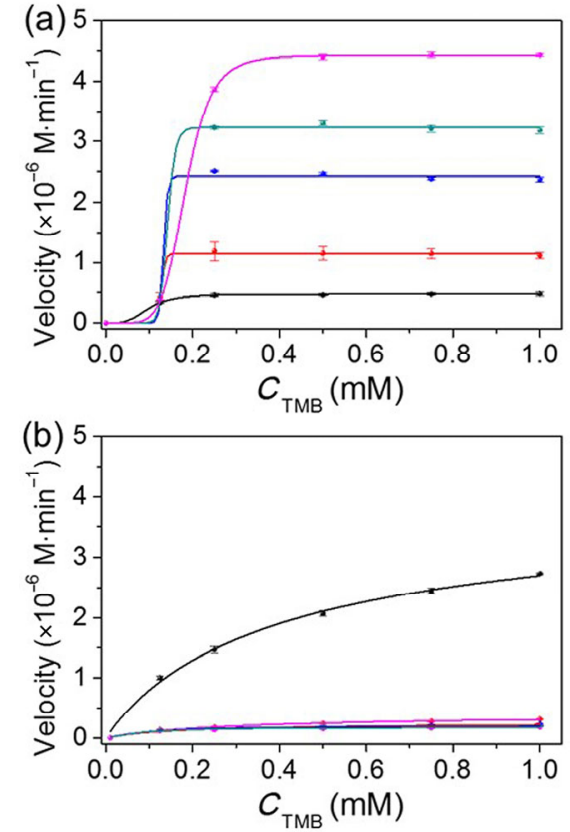

Figure 4 Typical kinetic analysis of (a) AuNPs and (b) HRP enzyme in the presence of varying TMB $(0-1.0 \mathrm{mM})$ and $\mathrm{H}_{2} \mathrm{O}_{2}$ concentrations (black: $0.0075 \%$, red: $1.0 \%$, blue: $2.0 \%$, cyan: $4.0 \%$ and pink: $6.0 \%$ ). Concentration of natural enzyme and nanozyme was fixed at $44.43 \mathrm{pM}$. Samples were analyzed in triplicate $(n=3)$ and standard deviation deduced from this data. Non-linear curve was fitted using the Hill equation.

TMB with a reaction velocity as high as $2.7 \times 10^{-6} \mathrm{M} \cdot \mathrm{min}^{-1}$ at $0.0075 \%$ $\mathrm{H}_{2} \mathrm{O}_{2}$. Interestingly, the activity of HRP decreases by 6.6 times when the $\mathrm{H}_{2} \mathrm{O}_{2}$ concentration is higher than $0.0075 \%$ (i.e. $V_{\max }=4.2 \times 10^{-7}$ at $1.0 \% \mathrm{H}_{2} \mathrm{O}_{2}$, and this maximum velocity decreases between $1.0 \%$ and $6.0 \% \mathrm{H}_{2} \mathrm{O}_{2}$, see Table S5 in the ESM for more details). This is contrary to that observed in the case of AuNPs acting as nanozymes. This reduced reaction speed is most likely due to enzyme inactivation caused by high $\mathrm{H}_{2} \mathrm{O}_{2}$ concentrations [41]. Importantly, this finding is useful in the tuning of the catalytic response. Thus, to minimize potential interference from contaminating peroxidase enzymes in clinical and veterinary samples and to promote the nanozyme activity, $6.0 \% \mathrm{H}_{2} \mathrm{O}_{2}$ was chosen for use in all experiments hereafter.

To test the hypothesis that coating the AuNP surface with casein results in the suppression of the peroxidase-mimicking activity, the following experiments were conducted. Firstly, uncoated-AuNPs and casein-AuNPs (at the same concentration of $44.43 \mathrm{pM}$ ) were mixed with $1.0 \mathrm{mM} \mathrm{TMB}$ and $6.0 \% \mathrm{H}_{2} \mathrm{O}_{2}$ solution and scanning kinetic analysis was carried out (Figs. 5(a) and 5(b)). It is evident in Fig. 5(a) that bare-AuNPs can catalyse for the oxidation of TMB in the presence of $\mathrm{H}_{2} \mathrm{O}_{2}$ instantaneously, resulting in the development of two distinct peaks at 370 and $650 \mathrm{~nm}$. The reaction demonstrates a substantial increase in absorbance at 370 and $650 \mathrm{~nm}$ with time, which agrees with the results in Fig. 3(c). Conversely, the caseincoated AuNPs demonstrate a much lower absorbance at 370 and $650 \mathrm{~nm}$ (Fig. 5(b)). The casein-coated AuNPs demonstrate a normalized absorbance at $370 \mathrm{~nm}$ of $0.7 \mathrm{OD}$, compared to $3.5 \mathrm{OD}$ for uncoated particles post incubation at room temperature for $20 \mathrm{~min}$ (Fig. 5(c)). This result is supported in Fig. 5(d) which demonstrates a reduced reaction velocity with the addition of casein layer onto the AuNP surface. Importantly, the catalytic activity of casein-coated AuNPs not only show suppression of peroxidase-mimicking activity at $6.0 \% \mathrm{H}_{2} \mathrm{O}_{2}$, but also at lower concentrations (down to $0.0075 \%$ ). For the full kinetic analysis of the casein-coated AuNPs in the presence of varying TMB and $\mathrm{H}_{2} \mathrm{O}_{2}$ concentrations, see the ESM (Fig. S4 and Table S5 in the ESM).

To fully characterize the peroxidase-mimicking activities of AuNPs, Michaelis-Menten catalytic parameters were calculated for 


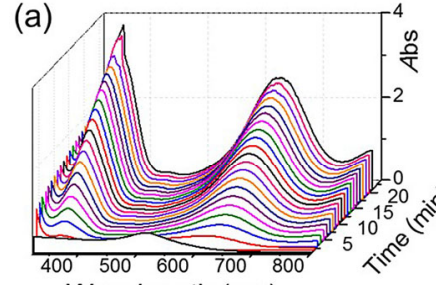

(C) Wavelength $(\mathrm{nm})$

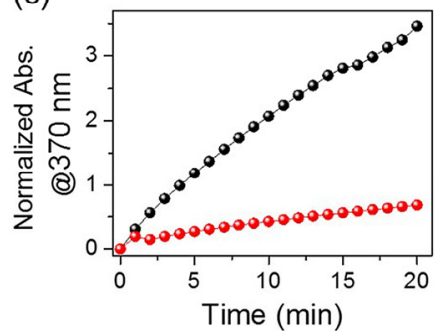

(b)

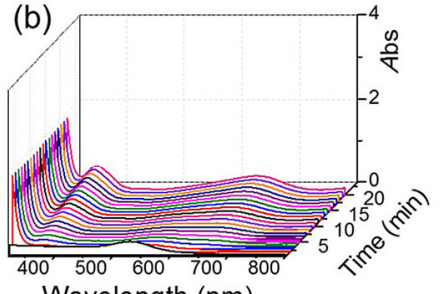
(d) -

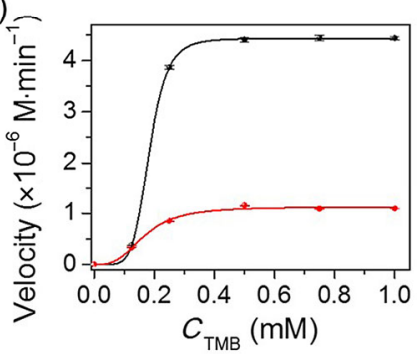

Figure 5 Spectral analysis demonstrating decreased peroxidase-mimicking activity of casein-AuNP (AuNP concentration $=44.43 \mathrm{pM}$ ). The spectra at time point zero indicates the wavelength of AuNPs prior to addition of $\mathrm{TMB} / \mathrm{H}_{2} \mathrm{O}_{2}$, demonstrating the plasmon peak around $520 \mathrm{~nm}$. Scanning kinetic analysis of (a) uncoated-AuNPs and (b) casein-coated AuNPs. (c) Kinetic analysis demonstrating suppressed activity of casein-AuNPs (red) and in the presence of $1.0 \mathrm{mM} \mathrm{TMB}$ / $6.0 \% \mathrm{H}_{2} \mathrm{O}_{2}$ compared to uncoated-AuNP (black). Values were normalized against $\mathrm{TMB} / \mathrm{H}_{2} \mathrm{O}_{2}$ solution incubated under the same conditions to remove background interference. (d) Reaction velocity of uncoated-AuNPs (black) and casein-AuNPs (red) over various TMB concentrations $\left(\mathrm{H}_{2} \mathrm{O}_{2}\right.$ concentration fixed at $\left.6.0 \%\right)$. Samples analyzed in triplicate $(n=3)$ and standard deviation deduced from this data. Non-linear curve was fitted using the Hill equation.

uncoated-AuNPs and casein-AuNPs over varying $\mathrm{H}_{2} \mathrm{O}_{2}$ concentrations $(0.0075 \%-6.0 \%)$ (Table S5 in the ESM). As previously discussed, we found that HRP had the highest $V_{\max }$ value at the lowest $\mathrm{H}_{2} \mathrm{O}_{2}$ concentration $(0.0075 \%)$, which subsequently decreased with increasing $\mathrm{H}_{2} \mathrm{O}_{2}$ concentration. This indicates that the reaction catalysed by HRP is limited by $\mathrm{H}_{2} \mathrm{O}_{2}$ concentration, resulting in a much lower maximal rate with increasing concentration. Conversely, for the uncoated AuNPs, the $V_{\max }$ increased by one order of magnitude with increasing $\mathrm{H}_{2} \mathrm{O}_{2}$ concentration up to $6.0 \%$. Between $0.0075 \%$ and $1.0 \% \mathrm{H}_{2} \mathrm{O}_{2}$ the $V_{\max }$ increased at the greatest rate from $4.9 \times 10^{-7}$ to $1.2 \times 10^{-6} \mathrm{M} \cdot \mathrm{min}^{-1}$ (2.4 times). The casein coated-AuNPs demonstrated a lower $V_{\max }$ over all $\mathrm{H}_{2} \mathrm{O}_{2}$ concentrations in comparison to the uncoated-AuNPs, indicating the ability of the coating molecules to slow the rate of substrate diffusion to the AuNP surface.

The Michaelis-Menten constant $\left(K_{\mathrm{M}}\right)$ was also calculated to provide more information on the substrate concentration required for the catalysis to occur. The results show a lower $K_{\mathrm{M}}$ value for the uncoatedand casein coated-AuNPs from $0.0075 \%-2.0 \% \mathrm{H}_{2} \mathrm{O}_{2}$, indicating less substrate is required for the catalysis to occur at a significant rate, compared to HRP enzyme. This lower value indicates a higher affinity towards the TMB substrate. For instance, at $2.0 \% \mathrm{H}_{2} \mathrm{O}_{2}$ concentration the uncoated and casein-coated AuNPs reach one half of its maximum speed $\left(1 / 2 V_{\max }\right)$ at a TMB concentration of $1.3 \times 10^{-1}$ and $1.4 \times 10^{-1} \mathrm{mM}$, respectively (Table S5 in the ESM). This finding is in agreement with Drozd and co-workers who found that the type of surface coating did not significantly impact the affinity of the AuNPs towards the substrate [42]. Conversely, for HRP this value is $1.8 \times 10^{-1} \mathrm{mM}$ at $2.0 \% \mathrm{H}_{2} \mathrm{O}_{2}$, demonstrating that a greater concentration of substrate is required to reach $1 / 2 V_{\max }$. However, above $2.0 \% \mathrm{H}_{2} \mathrm{O}_{2}$ the $K_{\mathrm{M}}$ begins to decrease for HRP, so to fully understand the differences in the reaction rate, the $k_{\text {cat }}$ was calculated. The results demonstrate reduced catalytic rate of the casein-AuNPs, confirming that the peroxidasemimicking activity had been suppressed in comparison to the uncoated-AuNPs over all $\mathrm{H}_{2} \mathrm{O}_{2}$ concentrations. In contrast with the uncoated-AuNPs, which had increasing catalytic rate with increasing
$\mathrm{H}_{2} \mathrm{O}_{2}$ concentration, the HRP enzyme had a decreased catalytic rate above $0.0075 \%$ (by 6.6 times). The catalytic efficiency $\left(k_{\text {cat }} / K_{\mathrm{M}}\right)$ of HRP correlates with this finding, demonstrating that at $0.0075 \%$ $\mathrm{H}_{2} \mathrm{O}_{2}$ the enzyme can convert more of the substrate it binds into product (Fig. 6). Conversely, for uncoated-AuNPs the catalytic efficiency increases between $0.0075 \%$ and $6.0 \% \mathrm{H}_{2} \mathrm{O}_{2}$. Interestingly, the uncoated-AuNPs have improved catalytic efficiency (up to 13 times at their best performance) in comparison to HRP enzyme. The casein-coated AuNPs demonstrate a consistent catalytic efficiency with increasing $\mathrm{H}_{2} \mathrm{O}_{2}$ concentration. From the results it was determined that the catalytic yield relative to the uncoated-AuNPs was as little as $22.9 \%$ for casein-AuNP (i.e. the intrinsic peroxidase-mimicking activity of AuNPs was suppressed by up to $77.1 \%$ ). These results demonstrate reduced catalytic efficiency of the casein coatedAuNPs due to decreased substrate diffusion onto the AuNP surface, caused by adsorbed casein molecules.

It is hypothesised that the peroxidase-mimicking activity of the coated AuNPs could be recovered if the casein shielding layer is disrupted. To fully elucidate the effect of enzyme cleavage on the peroxidase-mimicking activity of the coated AuNPs, maximum absorbance at $370 \mathrm{~nm}$ was used to monitor the production of oxTMB as a function of enzyme concentration $\left(0-2.0 \mathrm{mg} \cdot \mathrm{mL}^{-1}\right)$. The reaction was carried out in $0.1 \mathrm{M}$ PBS buffer $(\mathrm{pH} 7)$ for optimal enzyme activity. Figure 7(a) demonstrates the colorimetric response generated by casein coated-AuNPs in the presence of protease enzyme (enzyme activity $\left.=2 \mathrm{U} \cdot \mathrm{mg}^{-1}\right)$. A visible increase in intensity was noted with increasing concentration of protease enzyme from 0 to $2.0 \mathrm{mg} \cdot \mathrm{mL}^{-1}$, with the lowest concentration easily observed by the naked-eye determined at $100 \mathrm{ng} \cdot \mathrm{mL}^{-1}$. Figure 7(b) demonstrates an increase in peak absorbance at $370 \mathrm{~nm}$ with increasing enzyme concentration up to $2.0 \mathrm{mg} \cdot \mathrm{mL}^{-1}$. These findings are reiterated in Fig. 7(c) where there is an increase in absorbance at $370 \mathrm{~nm}$ with increasing protease concentration from 0 to $2.0 \mathrm{mg} \cdot \mathrm{mL}^{-1}$ (or from $0-10 \mathrm{U} \cdot \mathrm{mL}^{-1}$ ). Based on the linear fitting $\left(R^{2}=0.983\right)$, the limit of detection (LOD, three times the standard deviation of the blank sample, $3 \sigma$ ) of the nanosensor was determined as low as $44 \mathrm{ng} \cdot \mathrm{mL}^{-1}$ of protease (or equivalent to $2.2 \times 10^{-4} \mathrm{U} \cdot \mathrm{mL}^{-1}$ ). The sensitivity of the nanozyme approach is not strikingly predominant compared to those reported previously [24, 25, 43-45], however the assay time and design of coating agent warrants improved capabilities beyond that of current methods. The majority of the reported methods utilise peptides as the enzyme substrates, when, compared to casein which is used in the current approach, increases the overall cost of the assay as well as the time involved in peptide probe design. For example, peptide functionalised-AuNPs require design of specific, cleavable sequence

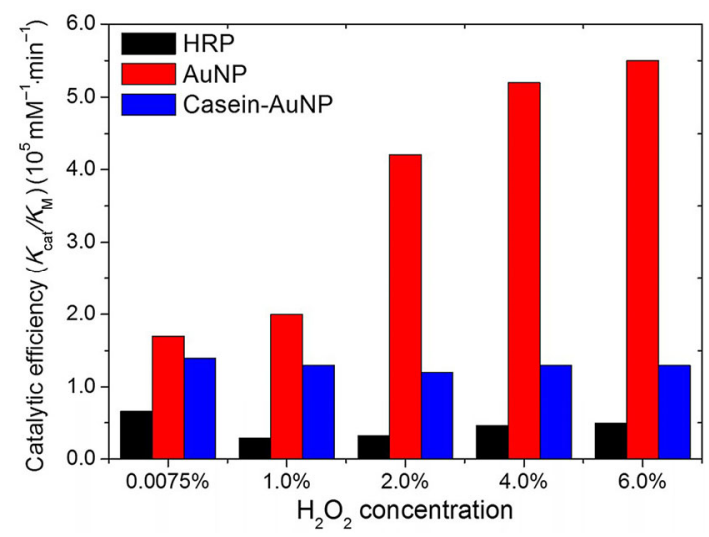

Figure 6 Comparison of catalytic efficiency of HRP, uncoated AuNPs and casein-AuNPs. The reaction was carried out in the presence of $1.0 \mathrm{mM}$ TMB and various $\mathrm{H}_{2} \mathrm{O}_{2}$ concentrations for $10 \mathrm{~min}$ at room temperature. Concentration of natural enzyme and nanozyme was fixed at $44.43 \mathrm{pM}$ and absorbance was measured at $370 \mathrm{~nm}$. 

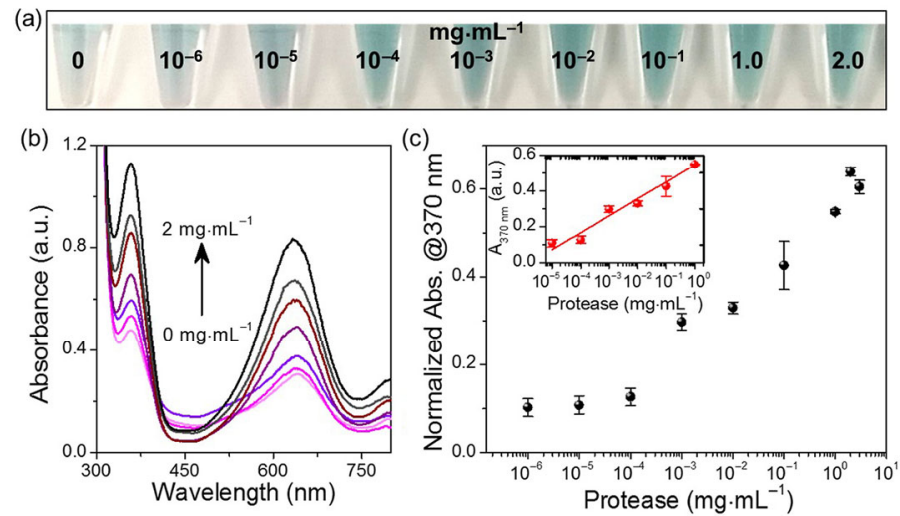

Figure 7 Naked-eye and spectroscopic analysis of casein coated AuNPs with increasing concentration of enzyme. (a) Colorimetric response with increasing concentration of protease $\left(0-2.0 \mathrm{mg} \cdot \mathrm{mL}^{-1}\right.$, enzyme activity $\left.=5 \mathrm{U} \cdot \mathrm{mL}^{-1}\right)$. (b) Absorption spectra for casein-coated AuNPs with increasing concentration of protease. (c) Normalised absorbance at $370 \mathrm{~nm}$ as a function of protease concentration (inset is the linear fitting, $R^{2}=0.983$; standard deviation $(\sigma)$ was calculated from triplicate samples $(n=3))$. The results were normalized against the mean of three zero values to remove background signal.

and modification of anchoring group [24, 25, 44, 45]. Other methods utilise gelatine and 6-mercaptohexan-1-ol-AuNPs which requires a two-step functionalisation approach, including two incubations at $37{ }^{\circ} \mathrm{C}$ and several washing steps. This further complicates and extends the preparation of the nanosensors in comparison to the casein-AuNPs which require one incubation and one wash prior to use (can be achieved within $3 \mathrm{~h}$ ). The majority of comparable methods utilised AuNP aggregation or dispersion as the transduction signal $[24,43-45]$ which requires modification of probe, i.e. thiol groups to induce aggregation upon enzyme cleavage of substrate or inclusion of terminal cysteines to ensure AuNP stability. The latter method required further functionalisation of the AuNP surface with PEG to prevent unwanted interactions between cysteines and the enzyme [43]. The current nanosensor utilises casein which is inexpensive and readily available. As the approach is based on the degradation of casein on the AuNP surface and subsequent recovery of peroxidasemimicking activity, there is no further modification of the substrate or the surface required. Other methods require fluorescent labelling of probe and thus there is added expense in terms of modification and need for expensive read-out equipment, which is not conducive to on-site analysis [25]. The production of oxTMB provides a visual color response, which can be read without the need for expensive equipment. The approach requires an initial $60 \mathrm{~min}$ incubation step between the casein-AuNPs and the sample. This is followed by the direct addition of TMB/ $\mathrm{H}_{2} \mathrm{O}_{2}$ and a subsequent 30 min incubation step. The analysis time of $90 \mathrm{~min}$ is also an improvement over methods requiring 2 to $6 \mathrm{~h}[27,44]$. It must also be noted that the method developed by Guarise and group is limited by samples contaminated by bisthiols, which potentially give rise to false negative results and thus may restrict applications [45].

We have now obtained evidence that the peroxidase-mimicking activity of the casein-coated AuNPs is recovered if the shielding layer is disrupted. Clinical and veterinary samples contain different enzymes such as proteases, lipases, catalases, amylases, which potentially interfere with the degradation of the shielding layer. Therefore, to further investigate the selectivity against these natural enzymes, the applicability of the casein-AuNP nanosensor for the detection of protease biomarker was determined. Figure 8 demonstrates the cross-reactivity of protease (bovine pancreas), lipase (Candida rugosa), catalase (bovine liver) and amylase (porcine pancreas) on the degradation of casein layer coated on the AuNP surface. While protease shows strong catalytic activity at both low and high concentrations $\left(0.1\right.$ and $\left.5 \mathrm{U} \cdot \mathrm{mL}^{-1}\right)$, lipase, catalase, and

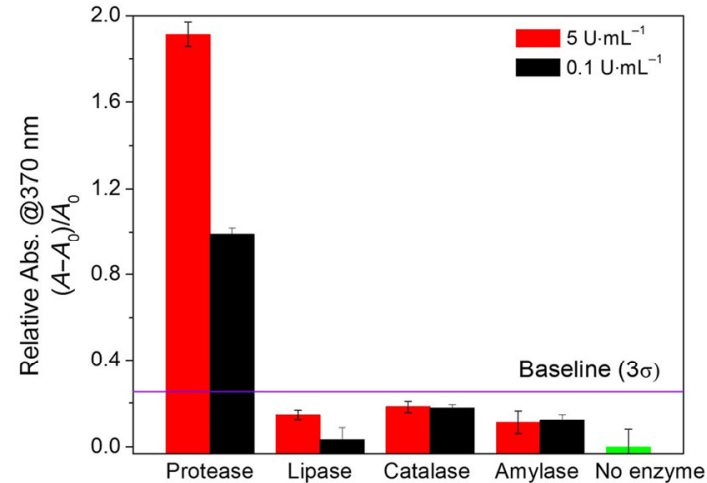

Figure 8 Cross-reactivity of common enzymes found in clinical and veterinary samples with the casein-coated AuNPs.

amylase do not exhibit any significant interference on the operation of the nanozyme nanosensor. Indeed, the relative absorbance value at $370 \mathrm{~nm}$ generated by these non-target enzymes is lower than the baseline level, which is defined as three times the standard deviation of the blank sample, $3 \sigma$, representing the high selectivity of the nanozyme nanosensor system.

As previously discussed, the detection of enzymes secreted in either bio-fluids or alongside microorganism growth can reveal infection, inflammation, contamination or disease conditions. Elevated amounts of protease in e.g. bovine milk, can provide information about microorganism spoilage or mastitis infection. Furthermore, protease enzymes are also found in urine of patients with diabetes and chronic renal failure. Therefore, various protease concentrations were spiked into bovine UHT milk and negative, synthetic human urine sample (certified reference material) to demonstrate the applicability of the approach. Figure 9(a) demonstrates the normalized absorbance at $370 \mathrm{~nm}$ as a function of protease concentration spiked in UHT milk. The results demonstrate good linearity $\left(R^{2}=0.94\right)$, with a linear range between $1.0 \mathrm{ng} \cdot \mathrm{mL}^{-1}$ and $100 \mu \mathrm{g} \cdot \mathrm{mL}^{-1}$ (equivalent to the enzyme activity of $5 \times 10^{-5}-0.5 \mathrm{U} \cdot \mathrm{mL}^{-11}$ ) and a LOD of $490 \mathrm{ng} \cdot \mathrm{mL}^{-1}$ (or $2.45 \times 10^{-3} \mathrm{U} \cdot \mathrm{mL}^{-1}$ ). The concentration of plasmin (a serine protease present in bovine milk) is relatively low in non-infected cattle. Richardson and Pearce (1981) reported a concentration of $0.14-0.73 \mu \mathrm{g} \cdot \mathrm{mL}^{-1}$ (labelled as green region in Fig. 9(a) as a visual guide) of plasmin in raw milk [46]. During an infection this concentration has been found to increase by 2.3 times in some cases (labelled as pink region, Fig. 9(a)) [47]. Thus, the reference levels suggests that our method is fully applicable to bovine mastitis detection in milk as the clinically relevant range falls within the dynamic range of the approach $\left(490 \mathrm{ng} \cdot \mathrm{mL}^{-1}-100 \mu \mathrm{g} \cdot \mathrm{mL}^{-1}\right.$, or $2.45 \times$ $\left.10^{-3}-0.5 \mathrm{U} \cdot \mathrm{mL}^{-1}\right)$. Figure 9 (b) shows the normalized absorbance at $370 \mathrm{~nm}$ as a function of protease concentration spiked in synthetic urine. A good linear response was observed $\left(R^{2}=0.97\right)$, with a wide dynamic range $1.0 \mathrm{ng} \cdot \mathrm{mL}^{-1}-2.0 \mathrm{mg} \cdot \mathrm{mL}^{-1}\left(\right.$ or $\left.5 \times 10^{-5}-10 \mathrm{U} \cdot \mathrm{mL}^{-1}\right)$, as well as a lower LOD of $176 \mathrm{ng} \cdot \mathrm{mL}^{-1}$ (or $\left.8.8 \times 10^{-4} \mathrm{U} \cdot \mathrm{mL}^{-1}\right)$. This lower detection limit in the urine sample is likely due to less matrix interferences compared to the complex milk matrix. In comparison to buffer conditions, the LOD for protease spiked into milk had increased by 11 times, or increased by 4 times for protease spiked into urine. Urinary serine protease activity has also been shown to be elevated in patients with diabetes, with the control group in one study displaying extremely low to no detectable level of protease. Patients with diabetic kidney disease have a measurable serine protease concentration of 0.4 to $1.3 \mu \mathrm{g} \cdot \mathrm{mL}^{-1}$ [48], which is significantly narrower than the clinical range of our developed nanozyme approach $\left(176 \mathrm{ng} \cdot \mathrm{mL}^{-1}-2.0 \mathrm{mg} \cdot \mathrm{mL}^{-1}\right)$. Thus, the nanozyme nanosensor demonstrates potential applicability as a rapid and low-cost screening tool for protease biomarker detection in both veterinary and clinical samples. 

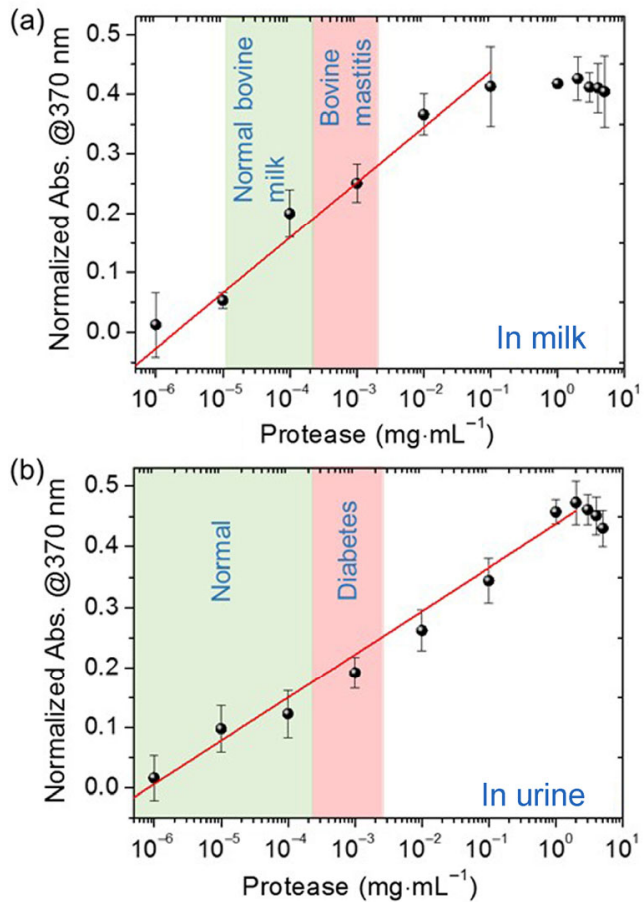

Figure 9 Relationship between normalized absorbance at $370 \mathrm{~nm}$ and increasing protease concentration spiked into (a) UHT milk $\left(R^{2}=0.94\right)$ and (b) urine $\left(R^{2}=0.97\right)$, demonstrating potential applications of the biosensor in food safety analysis and clinical and veterinary diagnosis of bacterial infections. Samples analyzed in triplicate $(n=3)$ and standard deviation deduced from this data. As a visual guide, the green and red labelled regions represent normal and disease cases (elevated), respectively.

\section{Conclusion}

In conclusion, we have developed a simple, low-cost and easyto-use nanosensor, based on the switchable peroxidase-mimicking activity of plasmonic AuNPs for the detection of proteolytic enzyme biomarker presented in urine and milk. Under experimental conditions, the peroxidase-mimicking activity of AuNPs was suppressed by up to $77.1 \%$ via coating with casein. Casein also provided binding recognition sites for protease, an enzyme biomarker indicative of disease or food spoilage. Without sophisticated and expensive read-out equipment, a result can be obtained in $90 \mathrm{~min}$, generating a strong blue color, visible by naked-eye and quantifiable by a simple colorimetry technique. In buffer conditions, the nanozyme nanosensor system can provide a LOD of $44 \mathrm{ng} \cdot \mathrm{mL}^{-1}$. The application for the detection of protease spiked in milk and urine samples has also been successfully demonstrated with an effective LOD of 490 and $176 \mathrm{ng} \cdot \mathrm{mL}^{-1}$, respectively, showing great promise as a screening tool for food safety and clinical diagnosis.

\section{Acknowledgements}

The author C. M. and N. L. thank the PhD studentship support from the Department of Employment and Learning for Northern Ireland (DEL); C. C. thanks the strong support from the Central Research Support Funds of Queen's University Belfast via a start-up grant, the support from the Agri-Food Quest Competence Centre $\mathrm{R} \& \mathrm{D}$ funding programme sponsored by Invest Northern Ireland Agency (Invest NI), and the support from the Queen's University of Belfast AMR Network (QUBAN) sponsored by the UK's Engineering and Physical Sciences Research Council (EPSRC).

Electronic Supplementary Material: Supplementary material (comparative overview of AuNP-based assays for the detection of protease enzyme (S1), optimization of casein concentration for surface coating of AuNPs (S2), TEM analysis of uncoated and casein coated-AuNPs (S3), reaction velocity of (a) uncoated-AuNPs and (b) casein-AuNPs over varying TMB (0-1.0 mM) and $\mathrm{H}_{2} \mathrm{O}_{2}$ concentrations (S4) and Michaelis-Menten kinetic parameters used to characterize the peroxidase-mimicking activities of HRP enzyme, bare-AuNPs and casein-AuNPs over various $\mathrm{H}_{2} \mathrm{O}_{2}$ concentrations (S5)) is available in the online version of this article at https:// doi.org/10.1007/s12274-018-2241-3.

Open Access: This article is distributed under the terms of the Creative Commons Attribution 4.0 International License (http:// creativecommons.org/licenses/by/4.0/), which permits unrestricted use, distribution, and reproduction in any medium, provided you give appropriate credit to the original author(s) and the source, provide a link to the Creative Commons license, and indicate if changes were made.

\section{References}

[1] Meisner, M. Biomarkers of sepsis: Clinically useful? Curr. Opin. Crit. Care 2005, 11, 473-480.

[2] Eckersall, P. D.; Bell, R. Acute phase proteins: Biomarkers of infection and inflammation in veterinary medicine. Vet. J. 2010, 185, 23-27.

[3] Fadda, S.; López, C.; Vignolo, G. Role of lactic acid bacteria during meat conditioning and fermentation: Peptides generated as sensorial and hygienic biomarkers. Meat Sci. 2010, 86, 66-79.

[4] Ossovskaya, V. S.; Bunnett, N. W. Protease-activated receptors: Contribution to physiology and disease. Physiol. Rev. 2004, 84, 579-621.

[5] Otlewski, J.; Jelen, F.; Zakrzewska, M.; Oleksy, A. The many faces of protease-protein inhibitor interaction. EMBO J. 2005, 24, 1303-1310.

[6] Zhang, S. G.; Janciauskiene, S. Multi-functional capability of proteins: $\alpha 1-$ antichymotrypsin and the correlation with Alzheimer's disease. J. Alzheimers Dis. 2002, 4, 115-122.

[7] Chen, J.; Li, L.; Chin, L. S. Parkinson disease protein DJ-1 converts from a zymogen to a protease by carboxyl-terminal cleavage. Hum. Mol. Genet. 2010, 19, 2395-2408.

[8] Travis, J.; Pike, R.; Imamura, T.; Potempa, J. The role of proteolytic enzymes in the development of pulmonary emphysema and periodontal disease. Am. J. Respir. Crit. Care Med. 1994, 150, S143-S146.

[9] Singh, R. B.; Dandekar, S. P.; Elimban, V.; Gupta, S. K.; Dhalla, N. S. Role of proteases in the pathophysiology of cardiac disease. Mol. Cell. Biochem. 2004, 263, 241-256.

[10] Medcalf, R. L. Fibrinolysis, inflammation, and regulation of the plasminogen activating system. J. Thromb. Haemost. 2007, 5, 132-142.

[11] Arora, P.; Ricks, T. K.; Trejo, J. Protease-activated receptor signalling, endocytic sorting and dysregulation in cancer. J. Cell Sci. 2007, 120, 921-928.

[12] Quirós, P. M.; Langer, T.; López-Otín, C. New roles for mitochondrial proteases in health, ageing and disease. Nat. Rev. Mol. Cell Biol. 2005, 16, $345-359$.

[13] Musante, L.; Tataruch, D.; Gu, D. F.; Liu, X. Y.; Forsblom, C.; Groop, P. H.; Holthofer, H. Proteases and protease inhibitors of urinary extracellular vesicles in diabetic nephropathy. J. Diabetes Res. 2015, 2015, 289734.

[14] Edgington-Mitchell, L. E. Pathophysiological roles of proteases in gastrointestinal disease. Am. J. Physiol. Gastrointest. Liver Physiol. 2016, 310, G234-G239.

[15] McCarty, S. M.; Cochrane, C. A.; Clegg, P. D.; Percival, S. L. The role of endogenous and exogenous enzymes in chronic wounds: A focus on the implications of aberrant levels of both host and bacterial proteases in wound healing. Wound Repair Regen. 2012, 20, 125-136.

[16] Koop, G.; van Werven, T.; Roffel, S.; Hogeveen, H.; Nazmi, K.; Bikker, F. J. Protease activity measurement in milk as a diagnostic test for clinical mastitis in dairy cows. J. Dairy Sci. 2015, 98, 4613-4618.

[17] Huis in't Veld, J. H. J. Microbial and biochemical spoilage of foods: An overview. Int. J. Food Microbiol. 1996, 33, 1-18.

[18] Shen, J. J.; Person, M. D.; Zhu, J. J.; Abbruzzese, J. L.; Li, D. H. Protein expression profiles in pancreatic adenocarcinoma compared with normal pancreatic tissue and tissue affected by pancreatitis as detected by two-dimensional gel electrophoresis and mass spectrometry. Cancer Res. 2004, 64, 9018-9026. 
[19] Wang, G. K.; Zhu, J. Q.; Zhang, J. T.; Li, Q.; Li, Y.; He, J.; Qin, Y. W.; Jing, Q. Circulating microRNA: A novel potential biomarker for early diagnosis of acute myocardial infarction in humans. Eur. Heart J. 2010, 31, 659-666.

[20] Rissin, D. M.; Kan, C. W.; Campbell, T. G.; Howes, S. C.; Fournier, D. R.; Song, L. N.; Piech, T.; Patel, P. P.; Chang, L.; Rivnak, A. J. et al. Singlemolecule enzyme-linked immunosorbent assay detects serum proteins at subfemtomolar concentrations. Nat. Biotechnol. 2010, 28, 595-599.

[21] Liao, H.; Wu, J.; Kuhn, E.; Chin, W.; Chang, B.; Jones, M. D.; O'Neil, S.; Clauser, K. R.; Karl, J.; Hasler, F. et al. Use of mass spectrometry to identify protein biomarkers of disease severity in the synovial fluid and serum of patients with rheumatoid arthritis. Arthritis Rheum. 2004, 50, 3792-3803.

[22] Lee, G.; Eom, K.; Park, J.; Yang, J.; Haam, S.; Huh, Y. M.; Ryu, J. K.; Kim, N. H.; Yook, J. I.; Lee, S. W. et al. Real-time quantitative monitoring of specific peptide cleavage by a proteinase for cancer diagnosis. Angew. Chem. 2012, 124, 5939-5943.

[23] Shi, L. F.; De Paoli, V.; Rosenzweig, N.; Rosenzweig, Z. Synthesis and application of quantum dots FRET-based protease sensors. J. Am. Chem. Soc. 2006, 128, 10378-10379.

[24] Chen, G. C.; Xie, Y. S.; Zhang, H. T.; Wang, P.; Cheung, H. Y.; Yang, M. S.; Sun, H. Y. A general colorimetric method for detecting protease activity based on peptide-induced gold nanoparticle aggregation. RSC Adv. 2014, 4, 6560-6563.

[25] Park, S. Y.; Lee, S. M.; Kim, G. B.; Kim, Y. P. Gold nanoparticle-based fluorescence quenching via metal coordination for assaying protease activity. Gold Bull. 2012, 45, 213-219.

[26] Ingram, A.; Byers, L.; Faulds, K.; Moore, B. D.; Graham, D. SERRS-based enzymatic probes for the detection of protease activity. J. Am. Chem. Soc. 2008, 130, 11846-11847.

[27] Tseng, C. W.; Chang, H. Y.; Chang, J. Y.; Huang, C. C. Detection of mercury ions based on mercury-induced switching of enzyme-like activity of platinum/ gold nanoparticles. Nanoscale 2012, 4, 6823-6830.

[28] Kim, S. H.; Park, M. K.; Kim, J. Y.; Chuong, P. D.; Lee, Y. S.; Yoon, B. S.; Hwang, K. K.; Lim, Y. K. Development of a sandwich ELISA for the detection of Listeria spp. using specific flagella antibodies. J. Vet. Sci. 2005, 6, 41-46.

[29] Hvolbæk, B.; Janssens, T. V. W.; Clausen, B. S.; Falsig, H.; Christensen, C. H.; Nørskov, J. K. Catalytic activity of Au nanoparticles. Nano Today 2007, 2, 14-18.

[30] Deng, H. H.; Weng, S. H.; Huang, S. L.; Zhang, L. N.; Liu, A. L.; Lin, X. H.; Chen, W. Colorimetric detection of sulfide based on target-induced shielding against the peroxidase-like activity of gold nanoparticles. Anal. Chim. Acta 2014, 852, 218-222.

[31] Zhao, D.; Chen, C. X.; Lu, L. X.; Yang, F.; Yang, X. R. A label-free colorimetric sensor for sulfate based on the inhibition of peroxidase-like activity of cysteamine-modified gold nanoparticles. Sens. Actuators B Chem. 2015, 215, 437-444.
[32] Hizir, M. S.; Top, M.; Balcioglu, M.; Rana, M.; Robertson, N. M.; Shen, F. F.; Sheng, J.; Yigit, M. V. Multiplexed activity of perAuxidase: DNA-capped AuNPs act as adjustable peroxidase. Anal. Chem. 2016, 88, 600-605.

[33] Shah, J.; Purohit, R.; Singh, R.; Karakoti, A. S.; Singh, S. ATP-enhanced peroxidase-like activity of gold nanoparticles. J. Colloid Interface Sci. 2015, 456, 100-107.

[34] Turkevich, J.; Stevenson, P. C.; Hillier, J. A study of the nucleation and growth processes in the synthesis of colloidal gold. Discuss. Faraday Soc. 1951, 11, 55-75.

[35] Haddadi, K.; Moussaoui, F.; Hebia, I.; Laurent, F.; Le Roux, Y. E. coli proteolytic activity in milk and casein breakdown. Reprod. Nutr. Dev. 2005, 45, 485-496.

[36] Cupp-Enyard, C. Use of the protease fluorescent detection kit to determine protease activity. J. Vis. Exp. 2009, 30, e1514.

[37] Bellino, M. G.; Calvo, E. J.; Gordillo, G. Adsorption kinetics of charged thiols on gold nanoparticles. Phys. Chem. Chem. Phys. 2004, 6, 424-428.

[38] Liu, Y.; Liu, L. L.; Yuan, M.; Guo, R. Preparation and characterization of casein-stabilized gold nanoparticles for catalytic applications. Colloids Surf. A Physicochem. Eng. Aspects 2013, 417, 18-25.

[39] Liu, Y.; Guo, R. pH-dependent structures and properties of casein micelles. Biophys. Chem. 2008, 136, 67-73.

[40] Wang, S.; Chen, W.; Liu, A. L.; Hong, L.; Deng, H. H.; Lin, X. H. Comparison of the peroxidase-like activity of unmodified, amino-modified, and citrate-capped gold nanoparticles. ChemPhysChem 2012, 13, 1199-1204.

[41] Arnao, M. B.; Acosta, M.; Del Rio, J. A.; García-Canovás, F. Inactivation of peroxidase by hydrogen peroxide and its protection by a reductant agent. Biochim. Biophys. Acta 1990, 1038, 85-89.

[42] Drozd, M.; Pietrzak, M.; Parzuchowski, P. G.; Malinowska, E. Pitfalls and capabilities of various hydrogen donors in evaluation of peroxidase-like activity of gold nanoparticles. Anal. Bioanal. Chem. 2016, 408, 8505-8513.

[43] Chuang, Y. C.; Li, J. C.; Chen, S. H.; Liu, T. Y.; Kuo, C. H.; Huang, W. T.; Lin, C. S. An optical biosensing platform for proteinase activity using gold nanoparticles. Biomaterials 2010, 31, 6087-6095.

[44] Laromaine, A.; Koh, L.; Murugesan, M.; Ulijn, R. V.; Stevens, M. M. Protease-triggered dispersion of nanoparticle assemblies. J. Am. Chem. Soc. 2007, 129, 4156-4157.

[45] Guarise, C.; Pasquato, L.; De Filippis, V.; Scrimin, P. Gold nanoparticlesbased protease assay. Proc. Natl. Acad. Sci. USA 2006, 103, 3978-3982.

[46] Richardson, B. C.; Pearce, K. N. The determination of plasmin in dairy products. N. Z. J. Dairy Sci. Technol. 1981, 16, 209-220.

[47] Politis, I.; Hang, K. F. N. K.; Giroux, R. N. Environmental factors affecting plasmin activity in milk. J. Dairy Sc. 1989, 72, 1713-1718.

[48] Buhl, K. B.; Oxlund, C. S.; Friis, U. G.; Svenningsen, P.; Bistrup, C.; Jacobsen, I. A.; Jensen, B. L. Plasmin in urine from patients with type 2 diabetes and treatment-resistant hypertension activates $\mathrm{ENaC}$ in vitro. $J$. Hypertens. 2014, 32, 1672-1677. 